Artículo

\title{
Germinación y vigor de semillas de especies hortícolas inoculadas con biofertilizantes y soluciones salinas
}

\author{
Santiago Ruiz-Ramirez ${ }^{1 \S}$ \\ Roberto Sánchez-Lucioº \\ Lily X. Zelaya-Molina ${ }^{3}$ \\ Ismael Fernando Chávez-Díaz ${ }^{3}$ \\ Carlos Iván Cruz-Cárdenas ${ }^{3}$ \\ Roberto Valdivia-Bernal ${ }^{4}$ \\ ${ }^{1}$ Campo Experimental Centro Altos de Jalisco-INIFAP. Av. Biodiversidad núm. 2470, Tepatitlán de \\ Morelos, Jalisco. CP. 47600. AP. 56. Tel. 800 0882222, ext. 84515. ${ }^{2}$ Campo Experimental Santiago \\ Ixcuintla-INIFAP. Entronque carretera internacional México-Nogales km 6, Colonia Centro, Santiago \\ Ixcuintla, Nayarit. Tel. 800 0882222, ext. 84427. (sanchez.roberto@inifap.gob.mx). ${ }^{3}$ Centro Nacional de \\ Recursos Genéticos-INIFAP. Boulevard de la Biodiversidad núm. 400, Rancho las Cruces, Tepatitlán de \\ Morelos, Jalisco. CP. 47600. Tel. 800 0882222, ext. 84823. (chavez.fernando@inifap.gob.mx; \\ zelaya.lily@inifap.gob.mx). ${ }^{4}$ Universidad Autónoma de Nayarit-Unidad Académica de Agricultura. \\ Carretera Tepic-Compostela km 9, Xalisco, Nayarit. Tel. 311 2110128. (rvald.uan@gmail.com). \\ ${ }^{\S}$ Autor para correspondencia: ruiz.santiago@inifap.gob.mx.
}

\section{Resumen}

El presente trabajo de investigación se realizó en Tepatitlán de Morelos, Jalisco, en las instalaciones del Campo Experimental Centro Altos de Jalisco. Se utilizaron semillas de especies hortícolas (chile chilaca, melón y pepino) inoculadas con biofertilizantes (Azospirillum brasilenses y Glomus intraradices) y sometidas a diferentes concentraciones de cloruro de potasio ( $\mathrm{KCl})$. El objetivo fue evaluar el efecto de los biofertilizantes y $\mathrm{KCl}$, en la germinación y vigor en semillas de especies hortícolas. Los tratamientos evaluados bajo condiciones de laboratorio fueron mediante la inoculación de biofertilizantes, combinación de biofertilizantes más solución salina en diferentes concentraciones, tratamiento químico y testigo absoluto, lo anterior para observar el efecto fisiológico en las semillas mediante las variables evaluadas: germinación estándar, longitud media de plúmula, vigor y peso seco. La información obtenida de cada una de las variables se analizó mediante un diseño completamente al azar con arreglo factorial y con cuatro repeticiones, siendo la unidad experimental los tacos (sustrato entre papel). Se detectaron diferencias significativas entre tratamientos y variables, esto debido a los resultados por inoculación de biofertilizantes en combinación con las concentraciones salinas, promovieron fisiológicamente las especies hortícolas en estudio siendo tratamientos T7 y T8, con mejor respuesta con respecto al testigo absoluto; es decir, tienen un efecto positivo en germinación y vigor en las especies estudiadas.

Palabras claves: biofertilizantes y especies hortícolas, vigor.

Recibido: mayo de 2021

Aceptado: julio de 2021 


\section{Introducción}

El suelo es el hábitat de una gran variedad de microorganismos las plantas alojan en su sistema radical una gran variedad de estos microorganismos interactuando con ellas de manera positiva o negativa. Los grupos dominantes son hongos, bacterias y nematodos (Manoharachary y Mukerji, 2006). La mayoría de estas interacciones ocurren en la rizósfera, un centro de actividades físicas, químicas y biológicas con apenas $1 \mathrm{~mm}$ de espesor, que rodea la arquitectura viva del sistema radical de una planta y que es influenciado por los exudados de la raíz (Cardon y Whitbeck, 2007).

Los microorganismos poseen una gran diversidad de mecanismos a través de los cuales promueven el crecimiento de las plantas. En función de estos mecanismos se reconocen cuatro grandes grupos de microorganismos promotores del crecimiento vegetal: a) microorganismos que incorporan nitrógeno al sistema planta-suelo mediante la fijación biológica de nitrógeno; b) microorganismos que incrementan la captación de nutrientes y agua; c) microorganismos que aumentan la disponibilidad de nutrientes en el suelo en formas no asimilables; y d) microorganismos que poseen actividades antagónicas contra agentes fitopatógenos (Aguado, 2012).

El empleo de microorganismos que viven en intercambio con las plantas es una de las áreas de estudio que más ha impactado la agricultura en las dos últimas décadas, debido a que son una alternativa emergente a los productos químicos, para incrementar la fertilidad y producción de cultivos en agroecosistemas sustentables (Franco-Correa, 2009; Rueda et al., 2009).

La salinidad es una limitante en cultivos hortícolas, que ocasiona alteraciones en el crecimiento, baja absorción y distribución de nutrientes a diferentes órganos de la planta y cambios en la calidad. El fertilizante cloruro de potasio constituyente de la mayor riqueza en potasio, buen porcentaje de solubilidad y además es de bajo costo en nuestro país (Ayala et al., 2019). Es por ello que el presente trabajo de investigación tiene como objetivo evaluar el efecto de los biofertilizantes y cloruro de potasio $(\mathrm{KCl})$, en la germinación y vigor en semillas de especies hortícolas.

En la agricultura actual, las nuevas variedades de alto rendimiento exigen mejores condiciones de cultivo y altos niveles de fertilización, y como consecuencia resulta en un deterioro ambiental que puede sobrepasar el beneficio económico, social y ambiental. De ahí la importancia de entender los efectos o mecanismos de los microorganismos que viven en asociación con las plantas. Los microorganismos ejercen un efecto benéfico sobre la germinación, desarrollo y control de otros microorganismos patógenos (biocontrolador) (Franco-Correa, 2009; Rueda et al., 2009).

Los inoculantes microbianos o biofertilizantes poseen en la actualidad gran relevancia ecológica y económica en la agricultura, por lo que su importancia se ha incrementado dentro de la conservación y la fertilidad de los suelos. Los hongos micorrícicos arbusculares (HMA) y las bacterias promotoras de crecimiento vegetal (BPCV), son de los microorganismos más estudiados (Adesemoye y Kloepper, 2009; Hungría et al., 2010; Sharma et al., 2012).

Clasificación de biofertilizantes. Los biofertilizantes se clasifican de acuerdo con el mecanismo(s) empleado por la bacteria para promover el crecimiento de las plantas (fijadores de nitrógeno, solubilizadores de fosfatos o desintegradores de materia orgánica) o bien conforme al tipo de microorganismos empleados en su formulación, bacterias, hongos o una combinación de ambos. 
Inoculantes bacterianos. Las rizobacterias más comúnmente aplicadas como inoculantes en la agricultura incluyen a las bacterias fijadoras de nitrógeno (diazotróficas) y las bacterias solubilizadoras de fosfatos. Los organismos diazotróficos emplean el complejo enzimático de la nitrogenasa para convertir nitrógeno atmosférico en amonio, un compuesto asimilable por las plantas y pueden ser de vida libre (Acetobacter, Azospirillum, Azotobacter, Bacillus, Beijerinckia, Enterobacter, Herbaspirillum, Klebsiella, Pseudomonas, Serratia y las cianobacterias Anabaena y Nostoc). (Bloemberg y Lugtenberg, 2001). En particular, el género Azospirillum se ha investigado a profundidad por su capacidad promotora del crecimiento vegetal y se ha convertido en un excelente modelo para estudiar la interacción planta-microorganismo.

Los resultados que han sido reportados con la asociación Azospirillum-planta son: a) incrementos en porcentaje y tasa de germinación; b) aumentos en la altura, peso fresco total, longitud radicular, mayor número de pelos y raíces adventicias y secundarias; c) incrementos en área foliar, repercutiendo en mayores índices de fotosíntesis y consiguiente mayor producción; d) incrementos en floración, espigamiento y amarre de fruto; y e) aumento en niveles de nitrógeno, expresados en proteína en el follaje y grano (Rueda et al., 2009) y producción de auxinas en la raíz (Star et al., 2012).

Inoculantes fúngicos. Los hongos que se han investigado más intensivamente como inoculantes fúngicos por sus beneficios en la nutrición de las plantas son las micorrizas, las micorrizas se dividen en ectomicorrizas y endomicorrizas. En el caso de Ectomicorrizas; Estas asociaciones simbióticas típicamente se forman entre las raíces de plantas leñosas y hongos pertenecientes a los Phylum Basidiomycota, Ascomycota y Zygomycota. Mientras que Las ectomicorrizas colonizan aproximadamente $10 \%$ de las familias de plantas que incluyen pinos, abedules, eucaliptos, encinos y hayas, entre otros. Las ectomicorrizas se pueden visualizar macroscópicamente pues el hongo rodea a la raíz y forma una capa o manto fúngico (Elo et al., 2000).

Endomicorrizas. Estos conforman un grupo muy variable de hongos que se clasifican en arbusculares, ericoides, arbutoides, monotropoides y orquidioides (Peterson et al., 2004). Las asociaciones de micorrizas arbusculares o AM (previamente conocidas como vesículo-arbusculares o VAM) son formadas únicamente por hongos pertenecientes al Phylum Glomeromycota. Las micorrizas arbusculares constituyen el grupo de hongos simbióticos más importante desde un punto de vista agrícola y ecológico. Actualmente son el grupo de hongos más empleado en la formulación de biofertilizantes y son fuertes candidatos para el biocontrol de fitopatógenos a través de sus capacidades competitivas por los espacios disponibles en las raíces (Aguado, 2012).

Algunos de los beneficios de las micorrizas en las plantas control de patógenos del suelo (Whipps, 2001) y estabilización de la estructura del suelo mediante un incremento en su agregación (Miller y Jastrow, 2000). Inoculantes compuestos. Existe un sinergismo en la promoción del crecimiento de las plantas cuando se emplean dos o más microorganismos estimuladores.

Sin embargo, la formulación de biofertilizantes compuestos que sean efectivos en campo requiere la realización de minuciosos estudios para conocer y entender los requerimientos nutricionales y ambientales de cada uno de los microorganismos a emplear en las formulaciones y los resultados de su interacción en términos fisiológicos y ecológicos para poder formular biofertilizantes que sean compatibles y sinérgicos en cuanto a sus efectos sobre las variables agronómicamente importantes de los cultivos, en campo o invernadero (Aguado, 2012). 
Desde hace varios años el empleo de bacterias y hongos solubilizadores de fósforo ha sido una práctica agrícola común en Rusia que ha dado buenos resultados. Asimismo, se ha demostrado que la combinación de distintas cepas de rizobacterias promotoras de crecimiento produce un efecto benéfico en arroz (Nguyen et al., 2002) y en cebada (Belimov et al., 1995). Asimismo, se ha encontrado que la combinación de rizobacterias promotoras de crecimiento vegetal y micorrizas arbusculares puede ser útil para incrementar el crecimiento de trigo en suelos de baja fertilidad (Galal et al., 2003). Así, se menciona a la co-inoculación de leguminosas con hongos arbusculares y Rhizobium resulta en un mejor crecimiento de las plantas que el que se obtiene utilizando cada uno de estos microorganismos por separado (Barea y Azcon-Aguilar, 1983; Bagyaraj, 1984).

Aunque el principal beneficio de los inoculantes duales es incrementar la absorción de nutrientes provenientes de los fertilizantes y del propio suelo (Belimov et al., 1995; Bashan et al., 2004), otros sinergismos pueden ser el resultado; por ejemplo, de un aumento en la captación de nutrientes y el control de agentes fitopatógenos. No obstante, los beneficios mencionados previamente en cuanto al empleo de biofertilizantes mixtos, duales o múltiples, es importante, realizar estudios a fin de determinar la compatibilidad de los microorganismos a aplicar ya que se han encontrado antagonismos entre algunos microorganismos promotores de crecimiento (Aguado, 2012).

\section{Materiales y métodos}

El presente trabajo de investigación se realizó en condiciones de laboratorio, en las instalaciones del Campo Experimental Centro Altos de Jalisco, se utilizaron semillas de especies hortícolas (chile chilaca, melón y pepino) inoculadas con biofertilizantes (Azospirillum brasilenses y Glomus intraradices) y sometidas a diferentes concentraciones de cloruro de potasio $(\mathrm{KCl})$.

Los tratamientos utilizados son los siguientes: T1= testigo absoluto (semillas sin inoculación y sin concentraciones salinas). $\mathrm{T} 2=$ tratamiento químico $\mathrm{AG}_{3}$ (ácido gibérelico) a $3 \mathrm{ppm}$. T3= semillas inoculadas Azospirillum brasilenses $(\mathrm{Az})+$ Glomus intraradices $(\mathrm{Gl})$. T4= semillas inoculadas con Az. T5 = semillas inoculadas con Gl. T6= semillas inoculadas $\mathrm{Az}+\mathrm{Gl}+5 \mathrm{dS} \mathrm{m}^{-1}$

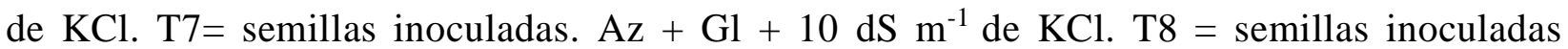
$\mathrm{Az}+\mathrm{Gl}+15 \mathrm{dS} \mathrm{m}^{-1} \mathrm{de} \mathrm{KCl}$.

Para dicho experimento se utilizaron 800 semillas de cada especie, de las cuales 500 semillas se inocularon con biofertilizantes (para el caso de los tratamientos 3, 4, 5, 6, 7 y 8), se requirió de $0.428 \mathrm{~g}$ de Azospirillum brasilenses y $0.802 \mathrm{~g}$ de Glomus intraradices, por cada gramo de semilla, para cada una de las especies estudiadas en este experimento, en el caso del tratamiento químico (T2) fue importante la incorporación debido a que su función es estimular la germinación y por ende la emergencia en campo, este se utilizó a la dosis recomendada a 3 ppm.

Las semillas se impregnaron con adherente y se mezclaron con los biofertilizantes en una caja de petri, una vez que se inocularon las semillas se procedió a realizar el ensayo de germinación según reglas ISTA (2004), para los cuales se utilizó hojas de papel anchor, agua destilada (para el caso del testigo absoluto). Durante el del ensayo de germinación se regaron los tacos (sustrato entre papel) con su respectiva dosis de $\mathrm{KCl}\left(5,10\right.$ y $\left.15 \mathrm{dS} \mathrm{m}^{-1}\right)$, mientras que para los tratamientos (T1 a T5) se regaron únicamente con agua destilada, al cuarto y séptimo día después de la siembra, siendo un total de siete días para las evaluaciones. 
Una vez establecido el experimento, las variables analizadas fueron los siguientes: germinación estándar o 'PN' (plántulas normales 'PN', plántulas anormales 'PA' y semillas sin germinar 'SSG') la evaluación se realiza al séptimo día después de la siembra. Para estos propósitos se define a la germinación, como la emergencia y desarrollo de aquellas estructuras esenciales que provienen del embrión y que manifiestan la capacidad de la semilla para producir una planta normal bajo condiciones favorables. Plántula normal se consideran todas aquellas que poseen las estructuras esenciales para producir plantas normales bajo condiciones favorables de agua, luz y temperatura.

Plántula anormal. Son aquellas plantas que presentan deficiencia en el desarrollo de sus estructuras esenciales, lo que les impide su desarrollo normal bajo condiciones favorables de agua, luz y temperatura. Semillas sin germinar Para esta clasificación es importante tomar en cuenta que las semillas que no germinan pueden ser por diferentes motivos, tales son los siguientes: semillas frescas, semillas duras, semillas muertas y semillas latentes, su expresión en porcentaje. Vigor (V) evaluación al cuarto día, únicamente se consideran plántulas normales y su expresión en porcentaje. Longitud media de radícula (LMR), longitud media de plúmula (LMP). Las pruebas de crecimiento de plántulas se realizan cuando las plántulas en un ensayo de germinación muestran todas sus estructuras esenciales y un desarrollo balanceado, son consideradas plántulas normales, al final del ensayo se cuenta el número de plúmulas que están situadas en cada paralela.

A las líneas se les da un valor de (0-2) 1, (2-4) 3, (4-6) 5, (6-8) 7, (8-10) 9, (10-12) 11 y (12-14) 13 $\mathrm{cm}$ valor del punto medio de cada paralela a la línea central. El número que queda en cada línea se multiplica por la correspondiente distancia y se suma, dividiendo la longitud total entre el número de semillas (25). Y peso seco (PS), se evalúan las plántulas descartando anormales, las plántulas normales se llevan a secado por $24 \mathrm{~h}$ a $80{ }^{\circ} \mathrm{C}$, después de eliminar la semilla o los cotiledones, después del secado se pesan hasta $\mathrm{mg}$, el peso seco total de las plántulas normales por repetición y

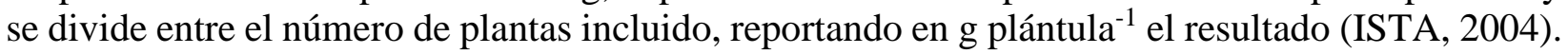

Análisis estadístico. La información obtenida de cada una de las variables estudiadas de la presente investigación, se analizó con el programa estadístico SAS 9.4, se utilizó un diseño completamente al azar, siendo la unidad experimental los tacos (sustrato entre papel), los tratamientos tuvieron arreglo factorial, con cuatro repeticiones, las cuales consistieron inoculaciones de biofertilizantes (Az y Gl) y en combinación con tres niveles de $\mathrm{KCl}\left(5,10\right.$ y 15 dS m $\left.{ }^{-1}\right)$, se realizó un análisis de varianza (Anova) y en las variables respuesta, donde se observó diferencia estadística significativa se hizo una comparación de medias (Tukey $p \leq 0.05$ ).

\section{Resultados y discusión}

Para esta sección se va a discutir de acuerdo con las variables y factores en estudio, como principal vamos a analizar el efecto en la germinación respecto a las variables y el efecto en el vigor y crecimiento de la planta respecto a las variables.

Efecto en la germinación. En el Cuadro 1, se analiza que existen diferencias significativas respecto a las especies utilizadas correspondientes a germinación estándar, plántulas anormales y semilla sin germinar, en lo que respecta al tratamiento y su interacción tratamiento*especie, no existe significancia en la germinación y en semillas sin germinar, caso contrario en plántulas anormales donde se presenta una alta significancia, lo que significa que en los tratamientos y combinaciones, el comportamiento en cuanto a su efecto en germinación, se presentó una respuesta independiente. 
Cuadro 1. Cuadrados medios de las variables analizadas.

\begin{tabular}{ccccc}
\hline Fuente de variación & GL & G $(\%)$ & PA $(\%)$ & SSG $(\%)$ \\
\hline Tratamiento & 7 & $52.23 \mathrm{~ns}$ & $47.02^{* *}$ & $9.18 \mathrm{~ns}$ \\
Especie & 2 & $6743.04^{* *}$ & $486.54^{* *}$ & $3650.79^{* *}$ \\
Tratamiento*especie & 14 & $41.51 \mathrm{~ns}$ & $33.39^{* *}$ & $24.64 \mathrm{~ns}$ \\
EE & 72 & 30.93 & 10.02 & 20.81 \\
Media & & 85.35 & 4.79 & 9.85 \\
CV & & 6.515821 & 66.08 & 46.3
\end{tabular}

${ }^{*} \mathrm{y}{ }^{* *}=$ valores significativos con $p \leq 0.05 \mathrm{y} p \leq 0.01$, respectivamente; $\mathrm{ns}=$ no significativo; $\mathrm{GL}=$ grados de libertad; $\mathrm{G}=$ germinación; $\mathrm{PA}=$ plántulas anormales; $\mathrm{SSG}=$ semillas sin germinar.

En la Figura 1, se observa que en el caso del chile chilaca el mejor resultado en base a la germinación respecto a los tratamientos con diferentes niveles de salinidad y combinación con biofertilizantes, obteniendo $8 \%$ más de germinación respecto al testigo absoluto y $7.5 \%$ con el tratamiento 2, lo cual nos indica que esta especie tolera la salinidad, mientras que para el melón no es tan tolerante a la salinidad y el mayor porcentaje de germinación se obtuvieron en el tratamiento $3(\mathrm{AZ}+\mathrm{Gl})$ y finalmente el pepino tuvo mejor porcentaje de germinación con el tratamiento 7 lo cual indica que tolera la salinidad.

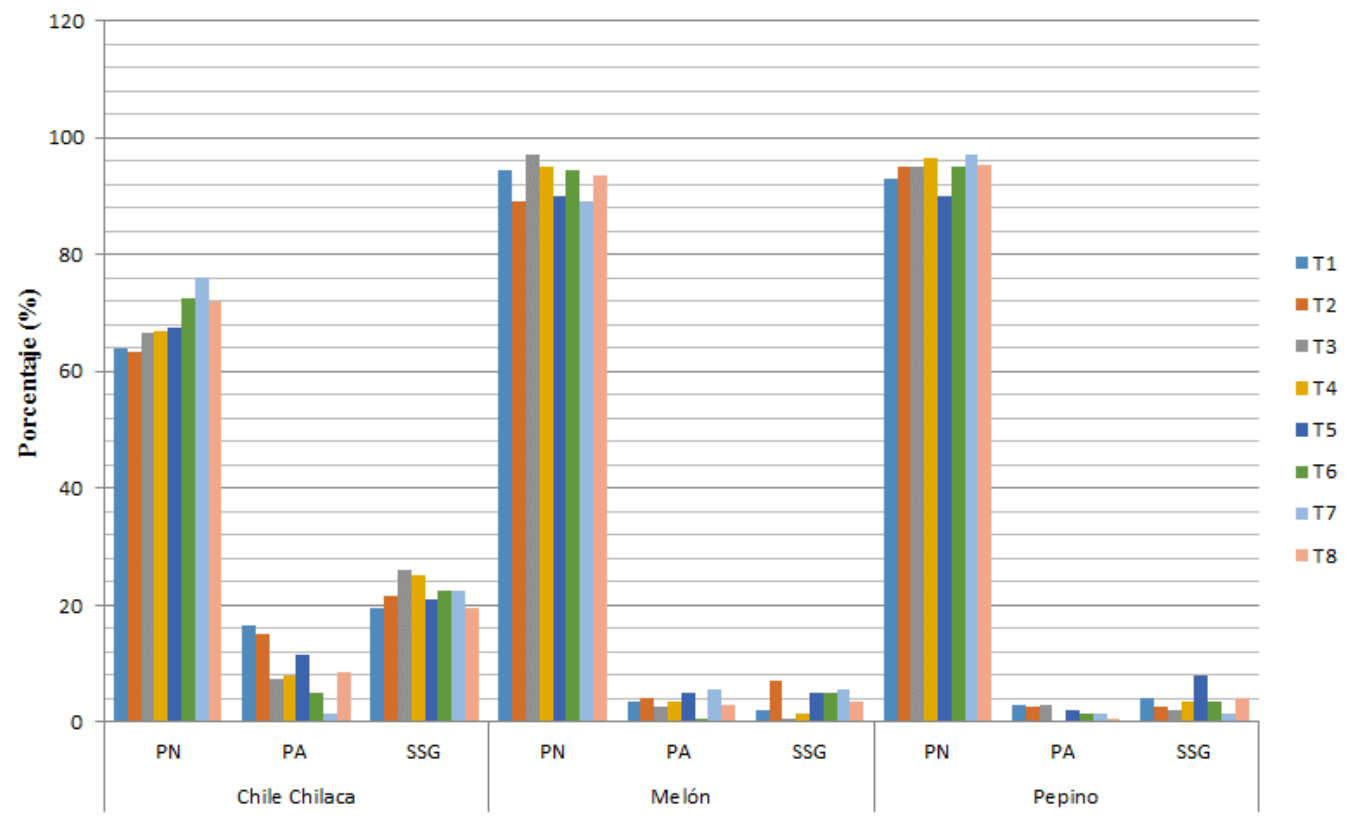

Figura 1. Comparación de medias del tratamiento/especie con respecto a la germinación (PN, PA y SSG).

El menor porcentaje de plántulas anormales o $(\%)$ de germinación en chile chilaca es para el tratamiento 7, siendo inverso el resultado con respecto al resultado de germinación; es decir, a mayor porcentaje de germinación tenemos menor porcentaje de plántulas anormales o en su caso SSG, para el melón el que tuvo menor porcentaje de plántulas anormales fue en el tratamiento 6 y para el pepino fue en el tratamiento 4. 
Lo que respecta a que para el chile chilaca el menor porcentaje de semillas sin germinar se observó en los tratamientos 1 y 8 , para el caso del melón fue el tratamiento 3 en el que se tuvo bajo porcentaje de semillas sin germinar y para el caso del pepino el tratamiento 7 fue el que tuvo un porcentaje mínimo de semillas sin germinar, logrando una sincronía en resultados con el porcentaje de germinación que es lo que se esperaba (Figura 1).

Efecto en el vigor y crecimiento de las plantas. En el Cuadro 2 se observa que existen diferencias altamente significativas en cuanto al desarrollo las plántulas entre los tratamientos, considerando LMP y LMR, asimismo y como indicativo de un componente fisiológico en las semillas el V y PS nos muestra que también existen diferencias, dichos resultados similares nos arroja en la interacción tratamiento*especie, mientras que en las especies evaluadas se percibe que en todas las variables analizadas existen diferencias altamente significativas.

Cuadro 2. Cuadrados medios de las variables analizadas, vigor y crecimiento de las plantas.

\begin{tabular}{cccccc}
\hline Fuente de Variación & GL & LMR $(\mathrm{cm})$ & LMP $(\mathrm{cm})$ & V $(\%)$ & PS $(\mathrm{g})$ \\
\hline Tratamiento & 7 & $4.97^{* *}$ & $39.45^{* *}$ & $245.27^{* *}$ & $0.08^{* *}$ \\
Especie & 2 & $542.82^{* *}$ & $935.31^{* *}$ & $13311.16^{* *}$ & $6.42^{* *}$ \\
Tratamiento*especie & 14 & $3.03^{* *}$ & $13.95^{* *}$ & $228.11^{* *}$ & $0.01^{* *}$ \\
EE & 72 & 1.03 & 0.58 & 26.06 & 0.005 \\
Media & & 11.82 & 12.57 & 81.47 & 0.64 \\
CV & & 8.61 & 6.08 & 6.26 & 11.05 \\
\hline
\end{tabular}

${ }^{*} \mathrm{y}{ }^{* *}=$ valores significativos con $p \leq 0.05$ y $p \leq 0.01$, respectivamente; $\mathrm{ns}=$ no significativo; GL= grados de libertad; LMR= longitud media de radícula; LMP= longitud media de plúmula; V= vigor y PS= peso seco de plántula.

Al analizar la (Figura 2a), se observa que, para las tres especies estudiadas, se tienen un mejor sistema radicular en el tratamiento 3; sin embargo, existe diferencia numérica entre ellas, podemos hacer énfasis que sigue reflejándose el desempeño de los biofertilizantes fusionados, seguido del tratamiento 4 y 5 , que sin duda están presentes los biofertilizantes, pero de manera individual.

En la (Figura 2b), se observa que para el caso del chile chilaca y el melón, el mejor resultado en cuanto al desarrollo de la plúmula está dado por el tratamiento 6, ya que, a pesar de la alta concentración de salinidad, los biofertilizantes desempeñaron adecuadamente la función, mientras que, para el pepino el mejor resultado se obtuvo en el tratamiento 8, el cual nos demuestra una vez más que a pesar de las altas concentraciones de salinidad, los biofertilizantes actúan logrando que las plántulas fisiológicamente presenten tolerancias a salinidad y vigor en la semilla.

El desarrollo de plántulas va acorde a lo reportado por Cruz-Romero et al. (2016), quienes, en su investigación, la inoculación con la cepa 7A de Azospirillum y la aspersión foliar de miel de abeja, demostraron que tienen efectos promotores del crecimiento vegetal, por lo tanto, constituyen una alternativa promisoria y viable para la producción de plántulas de hortalizas. Considerando que el vigor es uno de los parámetros más importantes en las semillas, se observa que chile chilaca y el pepino tuvieron un mayor porcentaje de vigor en el tratamiento 8, esto nos indica que estas especies son más tolerantes a la salinidad y que la inoculación de los biofertilizantes es una alternativa muy eficiente, mostrando diferencia respecto al testigo absoluto y tratamiento químico. Mientras que el melón presentó el mayor porcentaje de vigor en todos los tratamientos aun cuando la semilla es inoculada (oscilando entre 87.5 y $98 \%$ ), en los tratamientos 3 y 4 inoculadas con Az+Gl y Az, respectivamente, tal como se observa en la Figura 2c). 
Asimismo, Rojas y Ortuño (2007), en su trabajo de investigación concluyen que las plantas inoculadas con micorriza en combinación con humus de lombriz y gallinaza evaluados en el cultivo de cebolla, permitieron la obtención de altos rendimientos y un mayor desarrollo de la planta (mayor altura de planta, mayor diámetro de bulbo, mayor desarrollo radical, mayor vigor y mayor sanidad de las plantas) en ausencia de fertilizantes químicos.

Al observar los resultados en la (Figura 2d), deducimos que para el caso del chile chilaca y el melón, se generó mayor cantidad de materia seca en el tratamiento 7 y para el caso del pepino la mayor cantidad de materia seca se obtuvo en el tratamiento 6, enfatizando que la inoculación de los biofertilizantes, aumentaron considerablemente la materia seca de las plántulas, este resultado va paralelamente con lo obtenido en LMP, LMR, así como el vigor de la semilla, mostrando diferencias altamente significativas con respecto al testigo y mostrando un resultado considerable al interactuar los biofertilizantes en combinación con el cloruro de potasio Mujica y Batlle (2013).

Al realizar un análisis integral de los índices de crecimiento y desarrollo de las plantas evaluados en este ensayo (altura de las plantas, diámetro inferior y superior del tallo, número de flores y masa seca aérea) se comprobó la efectividad de la inoculación por capilaridad de la especie Glomus, destacándose, para todas las variables, las plantas inoculadas en relación con el testigo.
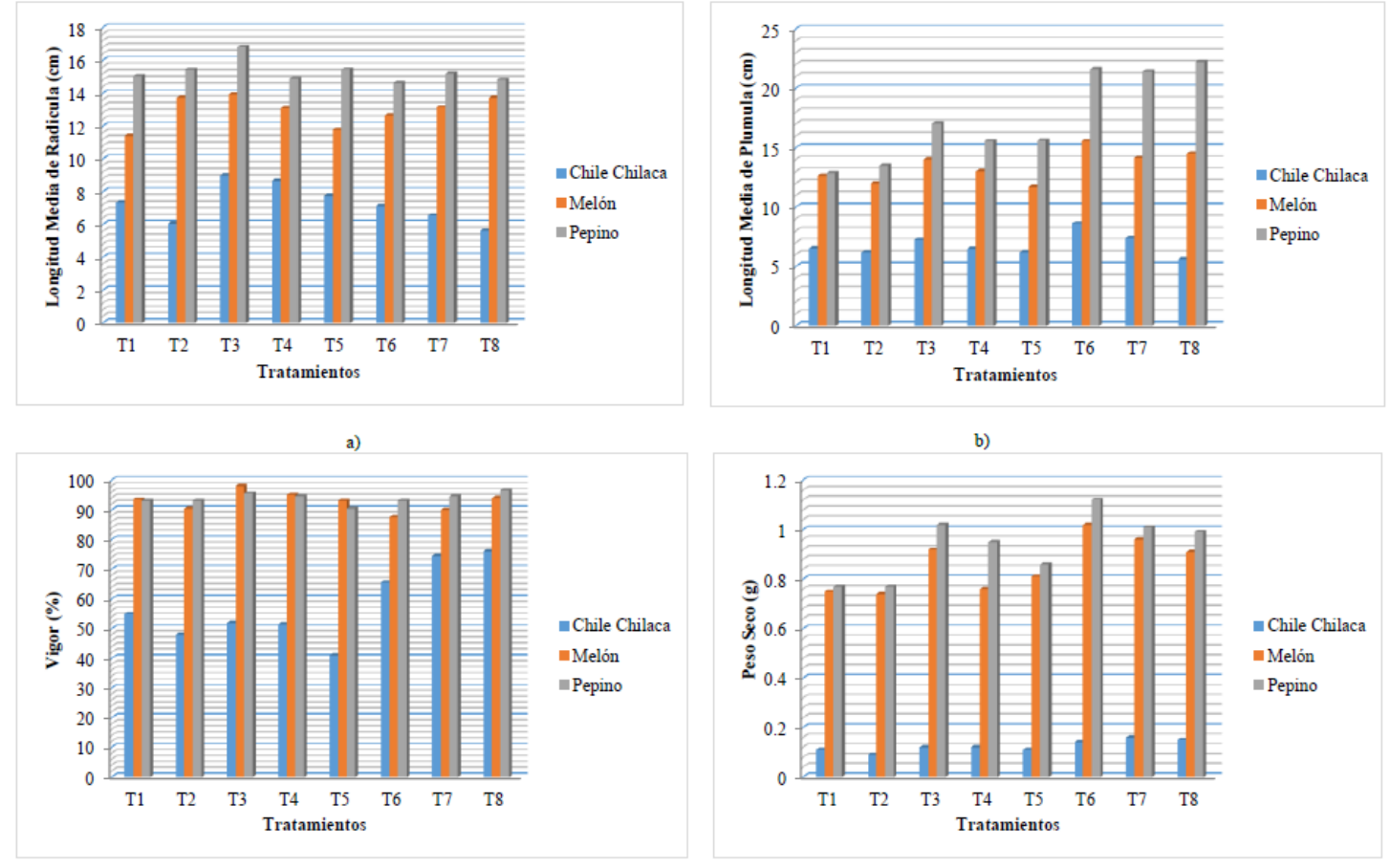

c)

d)

Figura 2. Comparación de medias de los tratamientos/especies. a) longitud media de radícula; b) longitud media de plúmula; c) vigor; y d) peso seco.

Al respecto, Parra y Cuevas (2001) indican que el mecanismo por el cual Azospirillum influye en el desarrollo y productividad de las plantas no es claro y entre las explicaciones señalan su capacidad para fijar $\mathrm{N}$ atmosférico en el suelo a través del incremento en la actividad de la enzima nitrato reductasa que estimula la asimilación de nitratos por las plantas inoculadas. 


\section{Conclusiones}

En base a los resultados obtenidos en la presente investigación, podemos concluir de manera concreta que la inoculación de biofertilizantes en las semillas en estudio tiene un efecto positivo en cuanto a las variables estudiadas.

Los resultados obtenidos por inoculación de biofertilizantes en combinación con las concentraciones salinas promovieron fisiológicamente las especies hortícolas en estudio siendo tratamientos T7 y T8 con mayor respuesta con respecto al testigo absoluto mostrando diferencias significativas; es decir, la combinación de los microorganismos y el cloruro de potasio, tienen un efecto positivo en germinación y vigor en las especies hortícolas.

\section{Literatura citada}

Adesemoye, A. O. y Kloepper, J. W. 2009. Plant-microbes interactions in enhanced fertilizer-use efficiency. Appl. Microbiol. Biotechnol. 85(1):1-12.

Ayala-Apaza, B. V.; Huanca-Chui, C. y Fernández-Chávez, C. M. 2019. Evaluación del cultivo de la lechuga (Lactuca sativa) en sistema hidropónico bajo dos niveles de cloruro de potasio. Rev. de Investigación e Innovación Agropecuaria y de Recursos Naturales. 6(2):66-71. http://www.scielo.org.bo/scielo.php?script=sci_arttext\&pid=S2409-16182019000200009 \&lng=es\&tlng=es.

Aguado, S. G. A. 2012. Introducción al uso y manejo de los biofertilizantes en la agricultura. In: Aguado-Santacruz, G. A. $1^{\text {a }}$ (Ed.). INIFAP/SAGARPA. México, DF. 35-37.

Bagyaraj, D. J. 1984. Biological interaction with VA mycorrhizal fungi. In: Mycorrhizae, V. A. Powell, C. and Bagyaraj, D. (Ed.). CRC Press, Boca Raton, FL. 240 p.

Barea, J. M. and Azcón-Aguilar, C. 1983. Mycorrhiza and their significance on nodulating nitrogen fixing plants. Adv. Agron. 36:1-54.

Bashan, Y.; Holguin, G. and de-Bashan, L. E. 2004. Azospirillum-plant relationships: physiological, molecular, agricultural, and environmental advances. Can. J. Microbiol. 50(8):521-577.

Belimov, A. A.; Kojemiakov, A. P. and Chuvarliyeva, C. V. 1995. Interaction between barley and mixed cultures of nitrogen fixing and phosphatesolubilising bacteria. Plant Soil. 173:29-37.

Bloemberg, G. V. and Lugtenberg, B. J. 2001. Molecular basis of plant growth promotion and biocontrol by rhizobacteria. Curr. Opin. Plant Biol. 4(4):343- 350.

Cardon, Z. G. and Whitbeck, J. L. 2007. The rhizosphere-an ecological perspective. Academic Press, San Diego, CA. 31-56 pp.

Cruz-Romero, W.; Barrios-Díaz, J. M.; Rodríguez-Mendoza, M. N.; Espinoza-Victoria, D. y Tirado-Torres, J. L. 2016. Producción de plántulas de hortalizas con Azospirillum sp. y aspersión foliar de miel de abeja. Rev. Mex. Cienc. Agríc. 7(1):59-70. http://www.scielo.org.mx/scielo.php?script=sci_arttext\&pid=S2007-09342016000100059 \&lng=es\&tlng=es.

Elo, S.; Maunuksela, L.; Salkinoja-Salonen, M.; Smolander, A. and Haahtela, K. 2000. Humus bacteria of Norway spruce stands: plant growth promoting properties and birch, red fescue and alder colonizing capacity. FEMS Microbiol. Ecol. 31(2):143-152. 
Franco-Correa, M. 2009. Utilización de los actinomicetos en procesos de biofertilización. Rev. Per. Biol. 16(2): 239-242.

Galal, Y. G. M.; El-Ghandour, I. A.; Osman, M. E. and Abdel, R. A. M. N. 2003. The effect of inoculation by mycorrhizae and rhizobium on the growth and yield of wheat in relation to nitrogen and phosphorus fertilization as assessed by $15 \mathrm{~N}$ techniques. Symbiosis. 34:171-183.

Hungría, M. Inoculation with selected strains of Azospirillum brasilense and A. lipoferum improves yield of maize and wheat in Brazil. Plant and Soil. 331:413-425.

ISTA. International Seed Testing Association. 2004. International rules for seed testing. PO Box 308, 8303 Basserdorf, CH-Switzerland. ISBN: 3-906549-38-0. Chapter 3, 4, 5 y 9.

Manoharachary, C. and Mukerji, K. G. 2006. Rhizosphere biology-an overview. In: Mukerji, K. G.; Manoharachary, C. and Singh, J. (Ed.), microbial activity in the Rhizosphere. Springer, German. 1-38 pp.

Miller, R. M. and Jastrow, J. D. 2000. Mycorrhizal fungi influence soil structure. In: arbuscular mycorrhizas: physiology and function. Kapulnik, Y. and Douds, D. (Ed.). Kluwer Academic Publishers, Dordrecht, The Netherlands. Chapter 1.

Mujica, P. Y. y Batlle, S. J. 2013. Funcionamiento de la inoculación líquida con hongos micorrízicos arbusculares (HMA) en plantas de tomate (Solanum lycopersicum L.). Cultivos Tropicales. 34(4):5-8. http://scielo.sld.cu/scielo.php?script=sci_arttext\&pid $=$ S0258- 59362013000400001\&lng=es\&tlng=es.

Nguyen, T. H.; Kennedy, I. R. and Roughley, R. J. 2002. The response of field grown rice to inoculation with a multi-strain biofertilizer in the Hanoi district, Vietnam. In: biofertilizers in action. Kennedy, I. R. and Choudhury, A. T. M. A. (Ed.). Rural Industries Research and Development Corporation, Barton, ACT. 37-44 pp.

Parra, Y. y Cuevas, F. 2001. Revisión bibliográfica. Potencialidades de Azospirillum como inoculante para la agricultura. Cultivos Tropicales. 23(3):31-41.

Rojas, R. K. y Ortuño, N. 2007. Evaluación de micorrizas arbusculares en interacción con abonos orgánicos como coadyuvantes del crecimiento en la producción hortícola del Valle Alto de Cochabamba, Bolivia. Acta Nova. 3(4):697-719. http://www.scielo.org.bo/scielo.php? script=sci_arttext\&pid=S1683-07892007000200005\&lng =es\&tlng=es.

Rueda, P. E.; Barrón, H. J. y Hallman, J. 2009. Bacterias promotoras del crecimiento vegetal. $1^{\text {a }}$ (Ed.). Plaza y Valdés. México. 141 p.

Sharma, S. 2012. Impact of application of biofertilizers on soil structure and resident microbial community structure and function. In: Maheshwari, DK. (Ed.). Bacteria in agrobiology: plant probiotics. New Delhi: Hauz Khas. 65-79 pp.

Star, L.; Matan, O.; Dardanelli, S. M.; Kapulnik, Y.; Burdman, S. and Okon, Y. 2012. The Vicia sativa spp. nigra Rhizobium leguminosarum bv. viciae symbiotic interaction is improved by Azospirillum brasilense. Plant Soil. 356:165-174.

Whipps, J. M. 2001. Microbial interactions and biocontrol in the rhizosphere. J. Exp. Bot. 52:487-511. 